\title{
CARPECTOMY AND PARTIAL ARTHRODESIS AS A SURGICAL INTERVENTION FOR UNILATERAL CONGENITAL FLEXION OF CARPAL JOINT IN A CROSSBRED HEIFER CALF: A CASE STUDY
}

\author{
Gamage DRK Perera*, Yasiru K. Jayawardana ${ }^{1}$ \\ Received 19June 2021, revised 06 October 2021
}

\begin{abstract}
A twenty-day old calf was presented to the Farm Animal Teaching Hospital with the complaint of inability to extend the left forelimb since the birth. The leg was congenitally flexed caudomedially at the carpal joint. Clinical examination and $\mathrm{X}$-ray images revealed the malformation of the carpal bones and the elective surgery was made under the general anesthesia with Xylazine $(0.05 \mathrm{mg} / \mathrm{kg}, \mathrm{IM})$ and Ketamine $(2 \mathrm{mg} / \mathrm{kg}$, IV). At the surgery, instead of six carpal bones only two (medial and lateral) were found. A wedge shaped $\left(\sim 15^{\circ}\right)$ slice of partial arthrodesis was performed at cranial parts of distal epiphysis of the radius and ulna bones. Similar arthrodesis was performed in proximal epiphysis of the metacarpus bone as well. The leg was extended and after infiltration of long-acting Penicillin; joint capsule, subcutaneous incisions and skin were sutured. Post-operative care was followed with wound dressing and parental injections of longacting Penicillin for 5 weeks. Until one month post operatively, the joint was immobilized with specially prepared 4-armed ('U' shape) metal splints. Six days after the surgery, the calf started to bear the weight using the operated limb. The calf was discharged with usual walking stance, and it was further confirmed 6 months later.
\end{abstract}

Key words: Carpal Joint, Calf, Congenital flexion, Carpectomy, Arthrodesis.

Anatomical and / or physiological abnormalities which are present at the birth regardless for its cause, in different systems of an animal or human are identified as congenital defects. Congenital defects may or may not be inherited. Primary causes for the above conditions are related with stresses due to the toxic, genetic (Johnson et al. 1985), infectious (Konno et al. 1982), nutritional or physical influences (Radostits et al. 2000). During the 285 days of gestation cows tolerate many stress factors such as changes of quality and quantity of the feed, (Abeygunawardena 1999, Perera 1999), administration of different medicines and exposure to the different climatic conditions (Lotfi and Shahryar 2009), infectious and noninfectious diseases, toxins, poisoning (Herschler et al. 1962) and anti-nutritive factors etc. However, in most of the congenital defects, the primary cause may not be identified due to the complexity of those (Radostits et al. 2000) causative factors.
Congenital flexural deformities are seen within $1^{\text {st }}$ two weeks of birth in calves. It ranges in severity from mild knuckling to being unable to stand and walk. The etiology of that deformity in cattle is generally unknown (Radostits et al. 2000). Specially, presence of defects and / or deformities in the carpal joints leads to functional limitation of the locomotor system with or without phenotypic abnormalities of the limb. Furthermore, congenital defects are one of the causes for culling of calves and it can result in economic losses to the industry as well. Such defects in the locomotor system are one of the major reasons for the above decision in dairy practice.

\section{Case history}

Twenty days old Friesian-Jersey-Sahiwal crossbred female calf was presented to the Farm Animal Teaching Hospital, Department of Farm Animal Production and Health, Faculty of Veterinary Medicine and Animal

Senior Clinician of Farm Animal Teaching Hospital, Senior Lecturer of Department of Farm Animal Production and Health, Faculty of Veterinary Medicine and Animal Science, University of Peradeniya, 24000, Sri Lanka.

${ }^{1}$ Clinician Farm Animal Teaching Hospital, Lecturer of Department of Farm Animal Production and Health, Faculty of Veterinary Medicine and Animal Science, University of Peradeniya, 24000, Sri Lanka.

*Corresponding author. e-mail: gdrkperera@gmail.com 
Science, University of Peradeniya, Sri Lanka with the complaint of inability to extend the left fore- limb at carpal joint since the birth (Fig. 1). It was a referred case from a small-scale dairy farm by the government veterinary surgeon in a remote area of the country.

\section{Clinical Examination}

On the clinical examination, all the physiological parameters (respiratory rate $28 / \mathrm{min}$, heart rate 102 beats/ min, pulse rate $102 / \mathrm{min}$, rectal temperature $102.8^{\circ} \mathrm{F}$ and PCV- 42 etc.) revealed the presence of good health status of the calf ensuring lower risk of general anesthesia. Although, the maximum flexibility of both carpal joints was more or less equal, extensibility was limited to approximately $80^{\circ}$ in left carpal joint. Similarly, it had further deviated medially in $20^{\circ}$ from its typical vertical axis (Fig. 1). External palpation of affected joint was supportive to understand the presence of carpal bones on cranial side and absence of those on caudal side of the joint.

Although diagnostic value was less due to unrecoverable error of the system, a left lateral x-ray image (Fig. 2. A) of the affected carpal joint was compared with the similar view of right carpal joint. Closer view of X-ray image of the left joint revealed the presence of single layer of wedge-shaped carpal bones on dorsal side which ended up at the center level of the joint. On palmar side, instead of the carpal bones, both radius and metacarpal bones were located close to each other (Fig. 2). Besides, caudal part of the distal epiphysis of the radius was shorter than its cranial part while palmar part of the proximal epiphysis of the metacarpus was shorter than its dorsal part.

\section{Anaesthesia}

After $4 \mathrm{hrs}$ fasting period, the calf was moderately sedated with $2 \%$ Xylazine $(0.05 \mathrm{mg} / \mathrm{kg}$, IM) ('Bromazine $2 \%$ ', New Zealand). Meantime, atropine sulphate $(0.06 \mathrm{mg} / \mathrm{kg}, \mathrm{IM})$ was administered prior to the anesthesia. After positioning on to the right lateral recumbency on the surgery table, it was anesthetized under $10 \%$ Ketamine ( $2 \mathrm{mg} / \mathrm{kg}$, IV) ('Ketamil', Australia). Head was lowered while tongue was exteriorized through the right lateral commissure of the opened mouth to reduce the anaesthetic risk. For the maintenance of anaesthesia, $20 \mathrm{mg}$ of Ketamine was used (Bishop 2001).

\section{Preparation of the surgical site}

The area of the affected carpal joint was clipped, and the site was scrubbed with isopropyl alcohol (70\%) [State Pharmaceutical Co. Ltd, Colombo, Sri Lanka] and Povidone iodine (10\%) [Central Drugs and Pharmaceuticals, Chennai, India] alternatively for three cycles in concentric pattern which was started from midline of the dorsal surface of the joint. Distal part of the leg was wrapped with a surgical drape and the surgical site was draped.

\section{Surgical procedure}

Four inches of longitudinal (vertical) skin incision on the dorsal surface of the affected joint was done. After applying of the respective incision through the

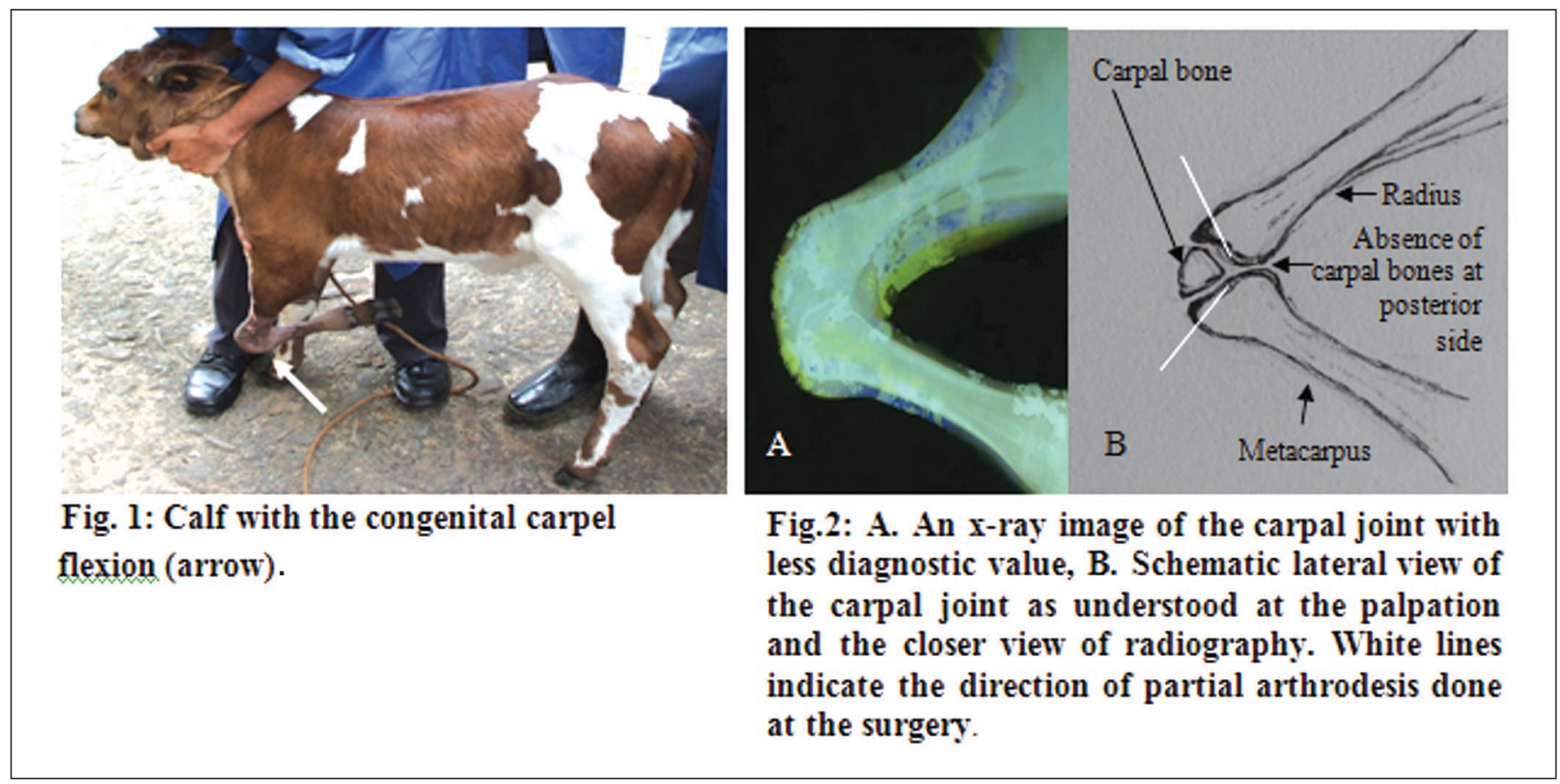



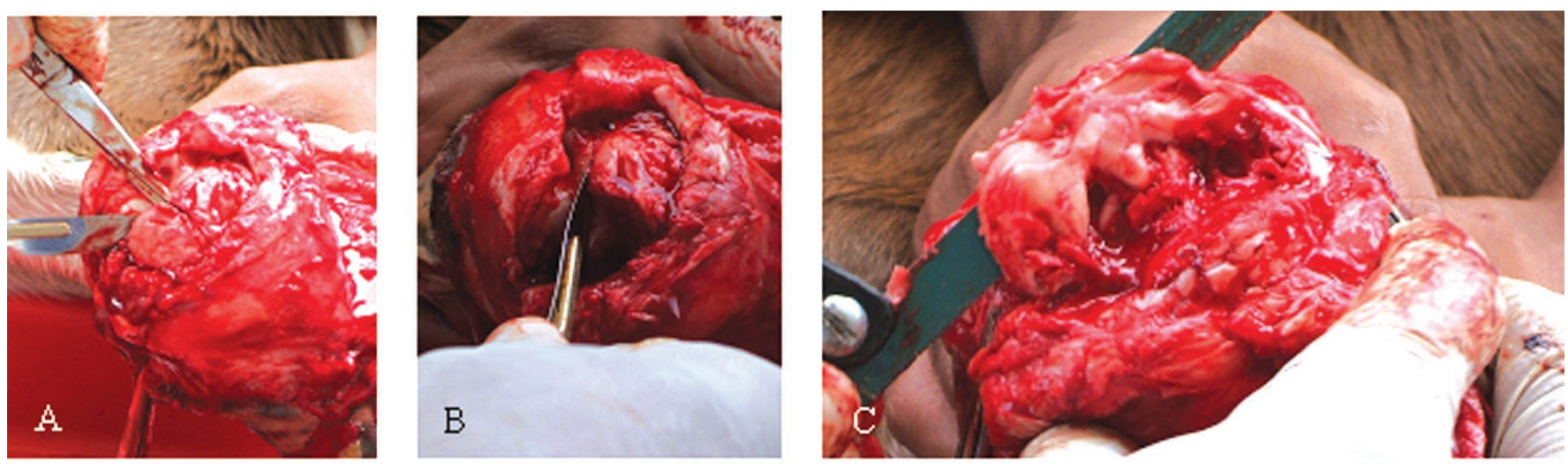

Fig. 3. Steps of the surgery: A. Removal of medial carpal bone, B. Removal of lateral carpal bone, C. Removal of a slice of distal epiphysis of Radius and Ulna bones.
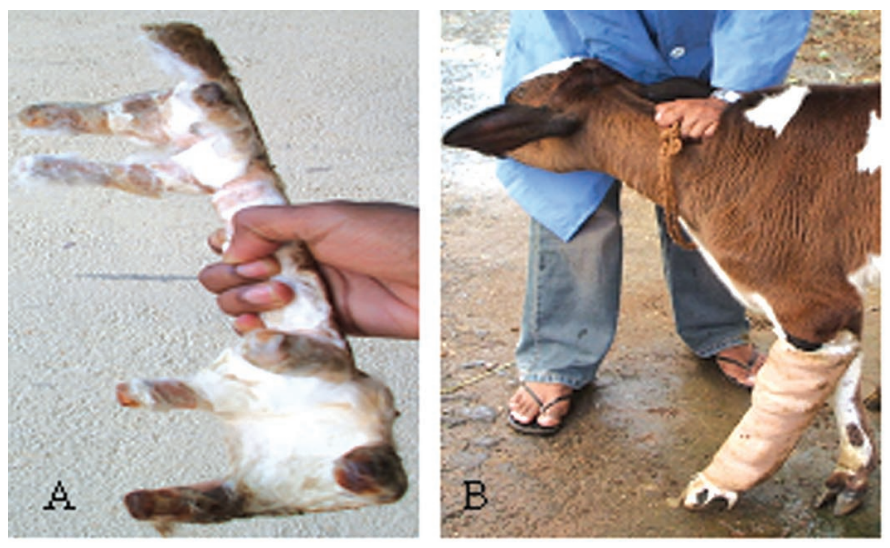

Fig. 4. External stabilization of the joint: A. Padded eightarmed mettle splints exclusively prepared for the calf. $B$. Start bearing the weight and walking with the mettle splint.

subcutaneous tissue, tendon of the extensor carpi radialis muscle was cut at the mid-level of it. Full length incision was made at mid vertical line of the joint capsule. The second incision was made horizontally at mid carpal level until exposure of the carpal bones. At the same level accessory cephalic vein was ligated and cut while several branches of radial artery (dorsal carpal branch of palmar branch and dorsal carpal branch) were separated with application of hemostats. Similarly, dorsal arterial plexus was cut partially. Instead of six, there were only two (medial and lateral) carpal bones at the joint. With further flexion of the joint and the separation of interosseous ligaments carpal bones were removed (Fig. 3. A and B). Due to inappropriate space, a wedge shaped $\left(\sim 15^{\circ}\right)$ slice from cranial epiphysis to mid of the articular surface of radius and ulna was removed. Also, a similar slice from metacarpus was removed (Fig. 2. B). The leg was extended similar to the maximum level of right front leg. After removal of the " $<,>$ shape" parts from each side of

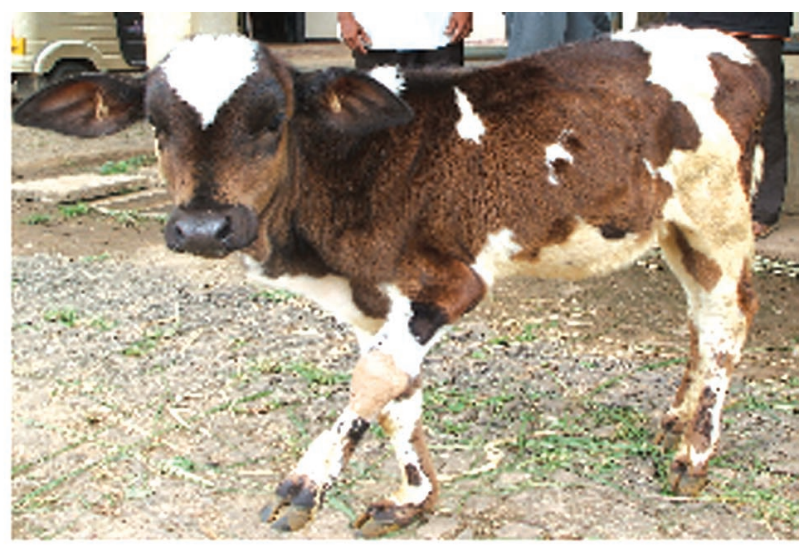

Fig. 5. One month after the surgery; the calf was walking without the splint.

the joint capsule and the skin associated with the horizontal incision, 66000 IU of benzathine Penicillin was infiltrated to the surgical site. Incision of the joint capsule was sutured with $3 / 0$ chromic cat gut (Ethicon, Division of Johnson and Johnson Ltd, Mumbai, India) using simple interrupted suture pattern. As such, after removal of a part (1"), the tendon of the extensor carpi radialis was sutured with same $3 / 0$ chromic cat gut using cross mattress suture pattern. The subcutaneous incision was sutured using the same type of suture material with simple continuous patterns. Skin incision was closed with $0.45 \mathrm{G}$ Nylon using simple interrupted suture pattern.

\section{Post-operative care}

At the end of the surgery the calf was injected with $1 \%$ flunixin meglumine $(1.1 \mathrm{mg} / \mathrm{kg}, \mathrm{IM})$ and twelve hours later, it was repeated (Radostits et al. 2000). Coumaphos, propoxur and sulpha nilamide containing wound dressing powder ('Negasunt', Bayer Polychem, India) and povidone iodine solution were mixed to prepare a wound dressing paste. It was applied on the surgical site and 
povidone iodine was applied on the entire shaved area of the leg.

A special metal splint which contained four ' $U$ ' shape arms (Fig. 4: A) was prepared for immobilizing the joint. It was padded with cotton wool and wrapped with cotton bandage. The splint was applied to the carpal joint of the affected leg from distal half of the radius- ulna to proximal half of the metacarpal area by using a selfadherent bandage ('3M- Coban', 3M Health Care, USA) (Fig. 4. B). A window of the bandage at the level of the surgical site which was covered with a separate piece of same bandage was left for the wound dressing procedures.

\section{Results and discussion}

Fifteen minutes post operatively the calf raised the head and turned to the sternal recumbency, gradually. Three hours later it stood up and started to walk in three legs walking stance. Six days after the surgery, the calf started to bear the weight using the particular limb on its own. One month post operatively the splint was removed and wound dressing was continued until another week period (Fig. 5). The calf was discharged with normal four leg walking stance and it was further confirmed 6 months later. It is very much important to confirm the presence of general health status which can affect the success before the surgery (Hickman et al. 1995). Similarly, assessment of the Pack Cell Volume level prior to the surgery was an important factor to decide the fitness of the calf for such a surgery with considerable possibility of bleeding. In this case it was closer to the upper margin of the normal range (24-46\%) (Radostits et al. 1994), without a measurable level of dehydration. In addition to the administration of atropine sulphate (Pugh 1991), tracheal intubation and lowering of the head can be practiced as a precautionary measure especially for the Xylazine induced salivation (Bishop 2001).

Although common digital extensor tendon was much close to the lateral edge of the horizontal incision, due to the flexion of the joint it could be managed without any damage. At the end of the surgery the affected leg was found to be shorter $\left(\approx 0.5^{\prime \prime}\right)$ than the counter leg. The calf was adapted to it in few days. Removal of caudal inter osseous ligaments of the carpal joint would be an optional way for such surgery. However, it would have the risk of leading to over extension making instability of the limb with many complications.

Surgical correction of the congenital malformations in fore limbs of calves due to defects in the carpal bones can be performed with success and it's a better solution in animal welfare aspect too.

\section{ACKNOWLEDGEMENT}

The authors are thankful to Dr. K.G.S.K. Senarathne, Government veterinary surgeon- Puttalam District, final year veterinary undergraduates and assistants of the hospital for their help during the period.

\section{REFERENCES}

Abeygunawardena H (1999) Reproductive management of cattle and buffaloes. In: Abeygunawardena H, Siriwardene JA, de S (eds.) Cattle and buffalo farming- a handbook for veterinarians. National Science Foundation Press, Sri Lanka. 123-139.

Bishop Y (2001) The Veterinary Formulary, $5^{\text {th }}$ edn, The British Veterinary Association, Great Britain. 361-414.

Herschler MS, Fechheimer NS, Gilmore LO (1962) Congenital abnormalities in cattle: their association with hereditary and environmental factors. J Dairy Sci 45(12): 14931499.

Hickman J, Houlton EFJ, Edwards B (1995) General surgical principles. In: Veterinary surgery, Blackwell Science Ltd, The University Press, Great Britain. 1-25.

Johnson JL, Leipold HW, Hudson DB (1985) Prominent congenital defects in Nebraska beef cattle. Breeding Reproduction 4(7): 1-8.

Lotfi A, Shahryar HA (2009) The case report of Taillessness in Iranian female calf (a congenital abnormality). Asian J Anim Vety Advances 4: 47-51.

Konno S, Moriwaki M, Nakagawa M (1982) Akabane disease in cattle: congenital abnormalities caused by viral infection, spontaneous disease. J Vety Pathology 19(3): 246266.

Perera O (1999) Management of reproduction.In: Falvey L, Chantalakhana C (eds) Smallholder dairying in the tropics, Intern Livestock Res Instit, Nairobi, Kenya. 241-264.

Radostits OM, Blood DC, Gay CC (1994) Veterinary Medicine, $8^{\text {th }}$ edn, W.B. Saunders, London. 1726-1727.

Radostits OM, Gay CC, Blood DC, Hinchcliff KW (2000) Veterinary Medicine, $9^{\text {th }}$ edn, W.B. Saunders, London. 115-152, 1823-1834.

*Cite this article as: Perera GDRK, Jayawardana YK (2021) Carpectomy and partial arthrodesis as a surgical intervention for unilateral congenital flexion of carpal joint in a crossbred heifer calf: a case study. Explor Anim Med Res 11(2): 251-254. DOI : 10.52635/eamr/11.2.251-254. 